\title{
Long-term Effect of Permanent Demyelination on Axonal Survival in Multiple Sclerosis
}

\author{
Alexandr Klistorner, PhD, * Samuel Klistorner, BSci, * Yuyi You, PhD, Stuart L. Graham, PhD, \\ Con Yiannikas, PhD, John Parratt, PhD, and Michael Barnett, PhD
}

Neurol Neuroimmunol Neuroinflamm 2022;9:e1155. doi:10.1212/NXI.0000000000001155

\section{Abstract}

\section{Background and Objectives}

To investigate the long-term effect of permanent demyelination on axonal attrition by examining an association between intereye asymmetry of the multifocal visual evoked potential (mfVEP) latency delay and subsequent thinning of retinal ganglion cell axons in patients with a long-standing history of unilateral optic neuritis (ON).

\section{Methods}

Only patients with a significant degree of chronic demyelination (intereye latency asymmetry $>5 \mathrm{~ms}$ ) were included in this study. The level of optic nerve demyelination was estimated at baseline by the latency delay of mfVEP, while the degree of axonal loss was assessed by thinning of the retinal nerve fiber layer (RNFL) thickness between baseline and follow-up visits. Lowcontrast visual acuity (LCVA) was also evaluated at baseline and follow-up. Patients were examined twice with an average interval of $6.1 \pm 1.4$ years.

\section{Results}

From 85 examined patients with multiple sclerosis, 28 satisfied inclusion criteria. Latency of the mfVEP was delayed, and RNFL thickness was reduced in ON eyes compared with fellow eyes at both visits. There was significant correlation between latency asymmetry and baseline or followup intereye RNFL thickness asymmetry. Intereye asymmetry of LCVA at baseline correlated with baseline latency asymmetry of mfVEP and baseline asymmetry of RNFL thickness. Latency of the mfVEP in ON eyes improved slightly during the follow-up period, whereas latency of the fellow eye remained stable. By contrast, RNFL thickness significantly declined in both ON and fellow eyes during the follow-up period. The rate of RNFL thinning in ON eyes, however, was more than 2 times faster compared with the fellow eyes $(p<0.001)$. Furthermore, baseline latency asymmetry significantly correlated with the rate of RNFL thinning in ON eyes during the follow-up $(p<0.001)$, explaining almost half of the variability of temporal RNFL progression. For each millisecond of latency delay (i.e., $\sim 0.5 \mathrm{~mm}$ of demyelination along the optic nerve), temporal RNFL thickness was annually reduced by $0.05 \%$.

\section{Discussion}

Our study provides clear in vivo evidence that chronic demyelination significantly accelerates axonal loss. However, because this process is slow and its effect is mild, long-term monitoring is required to establish and confidently measure the neurodegenerative consequences of demyelination.

\author{
Correspondence \\ Dr. Klistorner \\ sasha@eye.usyd.edu.au
}




\section{Glossary}

DMT = disease modifying therapies; LCVA = low contrast visual acuity; $\mathbf{m f V E P}=$ multifocal visual evoked potentials; MS = multiple sclerosis; OCT = optical coherence tomography; $\mathbf{O N}=$ optic neuritis; $\mathbf{R G C}=$ retinal ganglion cell; $\mathbf{R N F L}=$ retinal nerve fiber layer; RRMS = relapsing-remitting multiple sclerosis.

Multiple sclerosis (MS) is the most common cause of neurologic disability in young adults. Dysregulation of the adaptive immune system, a principal pathophysiologic driver of MS, results in inflammatory demyelination and progressive tissue injury.

The persistent clinical (disability) and radiologic (brain atrophy) features of early relapsing-remitting multiple sclerosis (RRMS) are primarily determined by substantial axonal damage within acute inflammatory lesions. ${ }^{1,2}$ However, although existing treatments significantly diminish the formation of new lesions, they do not fully arrest disease progression, ${ }^{3,4}$ suggesting the contribution of other, potentially neurodegenerative mechanisms.

The nature of the neurodegenerative mechanisms in MS is largely unknown. Although there are strong experimental data suggesting that ongoing CNS neurodegeneration is linked to the permanent loss of myelin sheaths surrounding surviving axons within MS lesions, ${ }^{5}$ human data on the role of chronic demyelination in MS progression are limited. ${ }^{6}$

There are several reasons why the visual system is an ideal model to study the effect of chronic demyelination on axonal loss. First, optic neuritis (ON), which leads to chronic demyelination in the optic nerve, is a frequent event in MS. It is the presenting symptom of MS in approximately $20 \%$ of cases and approximately $50 \%$ of patients with MS will experience symptomatic ON during the course of the disease. ${ }^{7}$ In addition, $\mathrm{ON}$ in MS is typically unilateral, which provides an internal control and reduces intersubject variability when using asymmetry analysis. ${ }^{8}$ Furthermore, the degree of demyelination can be objectively measured by the latency of multifocal visual evoked potentials (mfVEP), ${ }^{9}$ whereas optical coherence tomography (OCT) provides accurate estimation of retinal ganglion cell (RGC) axonal loss. ${ }^{10}$

Therefore, in this study, we used the visual system to examine the long-term effect of permanent demyelination on axonal attrition by investigating an association between intereye asymmetry of the mfVEP latency delay in patients with a longstanding history of unilateral $\mathrm{ON}$ and subsequent thinning of RGC axonal (as measured by retinal nerve fiber layer [RNFL] thickness), determined after an average interval of 6 years.

\section{Methods}

\section{Participants}

Eighty-five consecutive patients with relapsing-remitting MS (diagnosed based on the 2010 revised McDonald criteria ${ }^{11}$ ) were enrolled in this study. Patients with a history of other ocular or neurologic diseases were excluded.

All patients underwent low-contrast visual acuity (LCVA), mfVEP, and OCT testing. Patients with a history of unilateral $\mathrm{ON}$ at least 12 months before enrollment who reached at least 5 years of follow-up and had intereye latency asymmetry of more than $5 \mathrm{~ms}^{12}$ at the study baseline (indicating a significant degree of chronic optic nerve demyelination) were selected for further analysis. A numerical value of $5 \mathrm{~ms}$ was predefined based on the 95th percentile of mfVEP latency asymmetry in normal population. ${ }^{13}$

Time since the onset of ON was obtained from patient's records. The diagnosis of $\mathrm{ON}$ was based on clinical findings, which included an appropriate history and objective examination findings (decreased visual acuity, a visual field defect, color vision loss, relative afferent pupil defect, and a compatible fundus examination). The long-term data analyzed in this study were collected between July 2010 and June 2021.

\section{Standard Protocol Approvals, Registrations, and Patient Consents}

The study adhered to the tenets of the Declaration of Helsinki and was approved by the Human Research Ethics Committee of the University of Sydney. Written consent was signed by all participants.

\section{OCT Scans}

All patients had a peripapillary ring scan at baseline and follow-up using the Heidelberg Spectralis OCT as described previously. ${ }^{6}$ Data were reported following the APOSTEL recommendations. ${ }^{14}$ The same operator performed all scans. Both global and temporal RNFL thicknesses were analyzed. OSCAR-IB criteria ${ }^{15}$ were used to check image quality.

Owing to the fact that substantial thinning of the RNFL was present in ON eyes at baseline, the relative change of RNFL was used for analysis, as described previously. ${ }^{6}$

\section{Multifocal VEP Recordings and Analysis}

The level of demyelination in the visual pathways was assessed by the latency delay of mfVEP recorded using the Vision Search system (VisionSearch, Sydney, Australia) with standard stimulus conditions as described previously. ${ }^{16}$ In brief, 4 gold disk electrodes (Grass, West Warwick, RI) were used for bipolar recording with 2 electrodes positioned $4 \mathrm{~cm}$ on either side of the inion, 1 electrode $2.5 \mathrm{~cm}$ above, and another $4.5 \mathrm{~cm}$ below the inion in the midline. Electrical signals were recorded along 2 channels, measured as the difference between 
Figure 1 Flowchart of Patient Selection

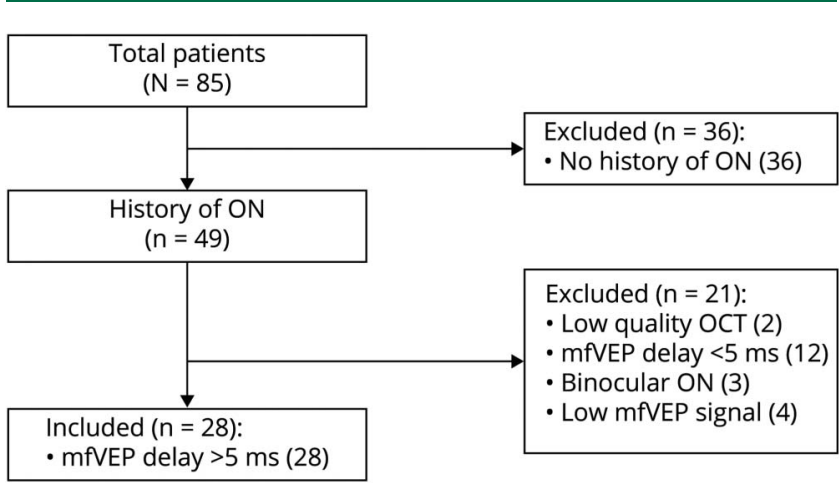

superior and inferior and between the left and right electrodes. The quality of the VEP signal was assessed by AIassisted in-house software, which was also used to estimate the latency of individual segments. Latency was calculated as the mean of 56 sectors. Because postchiasmal/optic radiation lesions are believed to affect latency of the mfVEP in a similar way, we used between-eye difference (asymmetry) to estimate the degree of demyelination in $\mathrm{ON}$ eyes.

\section{Low-Contrast Visual Acuity Recording and Analysis}

LCVA was tested unilaterally, using Sloan letter logarithmic translucent contrast charts at $2.5 \%$ and $1.25 \%$ contrast levels (Precision Vision, La Salle). Testing was performed on a retro-illuminated background at the distance of $4 \mathrm{~m}$. The charts were scored based on the number of letters identified correctly (maximum of 70 letters per chart). ${ }^{17}$

\section{Statistics}

Statistical analysis was performed using SPSS (version 24.0, IBM). The Pearson correlation coefficient was used to measure statistical dependence between 2 numerical variables. $p<$ 0.05 was considered statistically significant. Partial correlation was adjusted for age, sex, duration of the follow-up, and time since the onset of $\mathrm{ON}$. Comparisons between groups were made using the Student $t$ test. Longitudinal changes and difference between $\mathrm{ON}$ and fellow eyes were assessed using paired two-sample $t$ tests. The Shapiro-Wilk test was used to test the normal distribution.

\section{Data Availability}

Data can be made available on the request of other investigators.

\section{Results}

Of 85 patients with RRMS enrolled in this study, 49 had a clinical history of $\mathrm{ON}$ at least 12 months before the study. Of those, 28 patients satisfied the inclusion criteria and were selected for the analysis, presented in this study (see flowchart in Figure 1). Twenty-one patients (out of 85 patients) were
Table 1 Demographic Data

\begin{tabular}{ll}
\hline Sex (M/F) & $9 / 19$ \\
\hline Age, $\mathbf{y}$ & $38.1 \pm 9.6$ \\
\hline Disease duration at baseline, $\mathbf{y}$ & $5.0 \pm 4.8$ \\
\hline Time since onset of ON at baseline, $\mathbf{y}$ & $5.5 \pm 4.9$ \\
\hline EDSS & $1.2 \pm 0.9$ \\
\hline Duration of follow-up, $\mathbf{y}$ & $6.1 \pm 1.4$ \\
\hline Low-contrast visual acuity & ON eye fellow eye \\
\hline $\mathbf{2 . 5} \%$ baseline & $26 \pm 1638 \pm 11$ \\
\hline $\mathbf{1 . 2 5} \%$ baseline & $12 \pm 1125 \pm 14$ \\
\hline $\mathbf{2 . 5} \%$ follow-up & $23 \pm 1434 \pm 12$ \\
\hline $\mathbf{1 . 2 5} \%$ follow-up & $9 \pm 820 \pm 15$ \\
\hline
\end{tabular}

Abbreviations: EDSS = Expanded Disability Status Scale; ON = optic neuritis.

excluded because of the following: 4 patients had extremely low mfVEP amplitude (presumably caused by the severe damage of optic nerve fibers during acute $\mathrm{ON}$ ), 3 patients had binocular $\mathrm{ON}, 12$ patients had mfVEP latency asymmetry $<5$ $\mathrm{ms}$, and in 2 cases, the quality of OCT scans was low.

Patients selected for the analysis were examined twice with an average interval of $6.1 \pm 1.4$ years. Demographic data are provided in Table 1.

At study baseline, 4 patients were receiving interferon-based therapy, 6-copaxone, 8-gilenya, 3-tysabri, 2-aubagio, 2-tecfidera, and 1-ocrelizumab and 2 patients received no therapy. This has changed at the follow-up to the following: 1 interferon-based therapy, 3-copaxone, 6-gilenya, 2-tysabri, 1-aubagio, 4-tecfidera, 1-ocrelizumab, 5-ocrevus, 2-lemtrada, and 1-plegridy and 2 patients received no therapy.

\section{Association Between Cross-sectional Measures of Demyelination and Axonal Loss}

As expected, latency of the $\mathrm{ON}$ eyes was significantly delayed compared with fellow eyes at both baseline and follow-up visits $(p<0.001$ for both time points, Table 2$)$. Similarly, thickness of RNFL in ON eyes was significantly reduced compared with fellow eyes at both time points $(p<0.001$ for all, Table 2).

There was significant correlation between baseline intereye latency asymmetry and baseline intereye RNFL thickness asymmetry (both total and temporal RNFL thickness) ( $\mathrm{r}=$ $0.57, p=0.004$ and $\mathrm{r}=0.63, p=0.001$ for total and temporal RNFL thickness, respectively) (Figure 2, A and B), which remained significant after adjusting for age, sex, duration of the follow-up, and time since the onset of ON (partial correlation, $\mathrm{r}=0.49, p=0.016$ and $\mathrm{r}=0.55, p=0.005$ for total and temporal RNFL thickness, respectively). This relationship remained unchanged (if slightly higher) at the follow-up visit 
Table 2 Baseline and Follow-up mfVEP, RNFL, and LCVA Data

\begin{tabular}{|c|c|c|c|}
\hline & Baseline & Follow-up & $\begin{array}{l}p \text { Value } \\
\text { (baseline } \\
\text { vs follow-up) }\end{array}$ \\
\hline \multicolumn{4}{|l|}{ mfVEP latency } \\
\hline ON eye (ms) & $171.9 \pm 12.3$ & $169.3 \pm 12.9$ & $<0.001$ \\
\hline Fellow eye (ms) & $151.0 \pm 8.8$ & $151.3 \pm 8.7$ & 0.6 \\
\hline Asymmetry (ms) & $19.9 \pm 10.6$ & $17.1 \pm 10.1$ & $<0.001$ \\
\hline $\begin{array}{c}p \text { value (ON vs } \\
\text { fellow eyes) }\end{array}$ & $<0.001$ & $<0.001$ & \\
\hline \multicolumn{4}{|l|}{ Total RNFL } \\
\hline ON eye $(m)$ & $75.0 \pm 11.3$ & $73.2 \pm 11.2$ & $<0.001$ \\
\hline Fellow eye (m) & $88.3 \pm 11.1$ & $87.5 \pm 10.7$ & 0.026 \\
\hline Asymmetry (m) & $13.3 \pm 13.3$ & $14.3 \pm 12.9$ & 0.02 \\
\hline $\begin{array}{c}p \text { value (ON vs } \\
\text { fellow eyes) }\end{array}$ & $<0.001$ & $<0.001$ & \\
\hline \multicolumn{4}{|l|}{ Temporal RNFL } \\
\hline ON eye (m) & $47.4 \pm 11.6$ & $44.6 \pm 11.7$ & $<0.001$ \\
\hline Fellow eye (m) & $61.4 \pm 12.4$ & $59.9 \pm 12.1$ & $<0.001$ \\
\hline Asymmetry (m) & $13.9 \pm 14.9$ & $15.3 \pm 14.1$ & 0.02 \\
\hline $\begin{array}{c}p \text { value (ON vs } \\
\text { fellow eyes) }\end{array}$ & $<0.001$ & $<0.001$ & \\
\hline \multicolumn{4}{|l|}{ LCVA $2.5 \%$} \\
\hline ON eye & $26 \pm 16$ & $23 \pm 14$ & 0.004 \\
\hline Fellow eye & $38 \pm 11$ & $34 \pm 12$ & 0.002 \\
\hline $\begin{array}{l}p \text { value (ON vs } \\
\text { fellow eyes) }\end{array}$ & $<0.001$ & $<0.001$ & \\
\hline \multicolumn{4}{|l|}{ LCVA $1.25 \%$} \\
\hline ON eye & $12 \pm 11$ & $9 \pm 8$ & 0.02 \\
\hline Fellow eye & $25 \pm 14$ & $20 \pm 15$ & 0.001 \\
\hline $\begin{array}{l}p \text { value (ON vs } \\
\text { fellow eyes) }\end{array}$ & $<0.001$ & $<0.001$ & \\
\hline
\end{tabular}

Abbreviations: LCVA = low-contrast visual acuity; $\mathrm{mfVEP}=$ multifocal visual evoked potentials; ON = optic neuritis; RNFL = retinal nerve fiber layer.

$(\mathrm{r}=0.63, p=0.001$ and $\mathrm{r}=0.68, p<0.001$ for total and temporal RNFL thickness, respectively, or $\mathrm{r}=0.60, p=0.002$ and $\mathrm{r}=0.62, p=0.001$ for partial correlation, Figure 2, C and D).

LCVA was also significantly reduced in ON eyes compared with fellow eyes ( $p<0.001$ for both $2.5 \%$ and $1.25 \%$ contrasts). In addition, intereye asymmetry of LCVA at baseline correlated with the baseline latency asymmetry of mfVEP and baseline asymmetry of RNFL thickness, both total and temporal RNFL thickness (Table 3 and Figure 3).
Association Between Chronic Demyelination in $\mathrm{ON}$ and Subsequent Axonal Loss

Latency of the mfVEP in ON eyes improved slightly during the follow-up period (averaged shortening: $-2.6 \mathrm{~ms}, p<$ 0.001 ) (Table 2 and Figure 4A), whereas latency of the fellow eye remained stable $(p=0.6)$. This resulted in statistically significant reduction of latency intereye asymmetry between baseline and follow-up visits from 19.9 to $17.2 \mathrm{~ms}(p<0.001)$.

By contrast, we observed a significant reduction of total and temporal RNFL thickness in both $\mathrm{ON}$ and fellow eyes during the follow-up period (Table 2 and Figure 4, B and C). The rate of RNFL thinning in ON eyes, however, was significantly larger compared with the fellow eye (2.5\% vs $1.0 \%$ and $5.8 \%$ vs $2.2 \%, p=0.002$ and 0.001 for total and temporal RNFL thickness, respectively) (Figure 4, B and C). Accordingly, intereye asymmetry of RNFL thickness significantly increased during the follow-up period ( $p=0.02$ for both total and temporal RNFL thickness, Table 2).

Furthermore, the degree of chronic optic nerve demyelination (latency asymmetry at the baseline) was significantly associated with the annual rate of both total and temporal RNFL thinning in $\mathrm{ON}$ eyes (but not in fellow eyes) during the follow-up period $(\mathrm{r}=0.47, p=0.02$ and $\mathrm{r}=0.67, p<0.001$ for ON eye total and temporal RNFL thinning, respectively) (Figure 5, A and B). This correlation remained unchanged after adjustment for age, sex, and time since the onset of ON $(\mathrm{r}=0.52, p=0.028$ and $\mathrm{r}=0.68, p<0.001$ for total and temporal RNFL thickness, respectively). For each millisecond of latency delay at baseline (which is believed to be an equivalent of $\sim 0.5 \mathrm{~mm}$ of demyelination along the optic nerve ${ }^{18-20}$ ), temporal RNFL thickness was annually reduced by $0.05 \%$.

There was significant reduction of visual acuity in both $\mathrm{ON}$ and fellow eyes (Table 1). However, no correlation was observed between latency asymmetry at baseline and progressive change of LCVA in ON eyes. There was also no significant correlation in ON eyes between the reduction of LCVA and rate of RNFL thinning.

\section{Discussion}

The main finding of this study was the observation of an increased rate of RNFL thinning in ON eyes with a substantial degree of chronic demyelination in comparison with the fellow eyes in patients with RRMS. Thus, although RNFL thickness was significantly reduced in both eyes during the follow-up period, progressive thinning of total and temporal RNFL was more than 2 times faster in ON eyes compared with the fellow eyes. Furthermore, by examining the relationship between baseline intereye latency asymmetry and progressive change of RNFL thickness, we found a highly significant association between the degree of chronic optic nerve demyelination and subsequent loss of RGC axons in ON eyes. Chronic demyelination explained almost half of temporal RNFL progression variability. Of note, only patients 

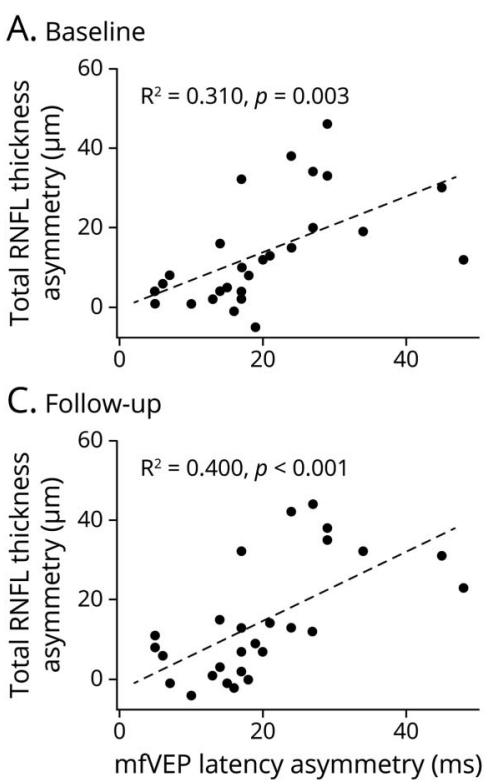

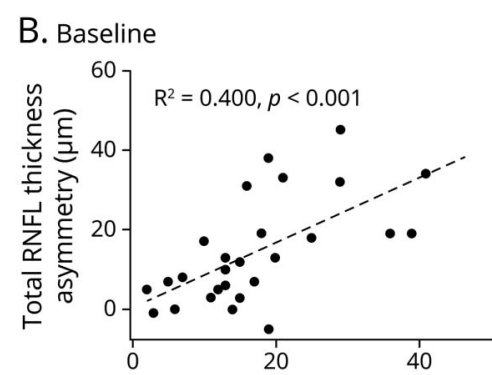

D. Follow-up

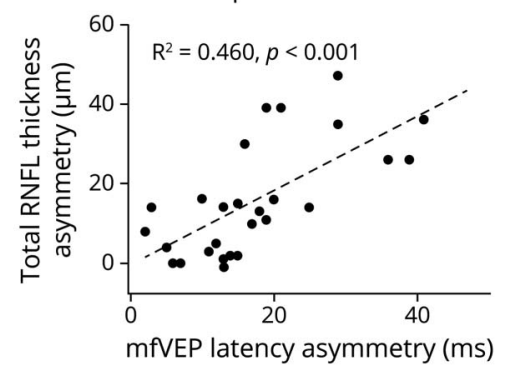

(A) Baseline intereye latency asymmetry vs baseline intereye total RNFL thickness asymmetry. (B) Baseline intereye latency asymmetry vs baseline intereye temporal RNFL thickness asymmetry. (C) Baseline intereye latency asymmetry vs follow-up intereye total RNFL thickness asymmetry. (D) Baseline intereye latency asymmetry vs follow-up intereye temporal RNFL thickness asymmetry. with clearly measurable chronic demyelination, as evidenced by substantial latency delay in the ON eyes, were included in this analysis.

These findings lend strong support to the notion that chronic demyelination does promote axonal loss. This view until now was mainly based on experimental data. It has been proposed that permanent demyelination may cause axonal damage by rendering axons vulnerable to physiologic stress ${ }^{21-23}$ by the way of increased energy demands on axonal conduction along demyelinated axons, leading to compromised axoplasmic adenosine triphosphate production, ${ }^{24}$ ionic imbalance, and $\mathrm{Ca}^{2+}$-mediated axonal degeneration. ${ }^{25}$ In addition, lack of trophic support from myelin or oligodendrocytes and the disruption of normal axon-myelin interactions were also implicated in the accelerated degeneration of chronically demyelinated axons. ${ }^{22}$ Furthermore, residual inflammation caused by infiltration of chronic lesions by macrophages and $\mathrm{T}$ cells and the activation and proliferation of astrocytes may also contribute to the ongoing damage of demyelinated axons. $^{23,26}$

However, although we did confirm the detrimental effect of chronic demyelination on axonal survival, suggested by the above experimental studies, the magnitude of the axonal loss caused by permanent demyelination seems to be very modest and is only detectable using a relatively long observation period (annual relative rate of RNFL thinning in $\mathrm{ON}$ eyes compared with fellow eyes was $+0.25 \%$ and $+0.6 \%$ for total and temporal RNFL thinning, respectively). This may explain why our previous investigations of the relationship between chronic demyelination and axonal damage produced less convincing results. 6,27
Our initial short-term study (mean follow-up: 2 years) ${ }^{27}$ demonstrated a marginally (but not significantly) faster rate of RNFL thinning in ON eyes compared with fellow eyes ( $1.5 \mathrm{vs}$ $1.3 \mu$ ) and did not show any association between RGC axonal loss and latency delay, with the caveat that a first generation temporal domain OCT was used in this study.

After this, a longer follow-up study (mean observation period: 3.5 years $)^{6}$ also demonstrated faster tRNFL thinning in ON eyes compared with the fellow eyes (1.3\% vs $1.0 \%$ tRNFL thinning per year), although was still not statistically significant for both total and temporal RNFL thinning. The survival analysis, however, demonstrated a significant difference between the 2 groups. Furthermore, in cases of more severe optic nerve demyelination, progressive loss of temporal (but not total) RNFL was significantly faster in the $\mathrm{ON}$ eyes than in the fellow eyes. In addition, faster loss of tRNFL significantly correlated with the degree of ON-related demyelination.

Table 3 Correlation Coefficient of Intereye Asymmetry of LCVA at Baseline With Baseline Latency Asymmetry of mfVEP and Baseline Asymmetry of RNFL Thickness

\begin{tabular}{lll}
\hline & LCVA 2.5\% & LCVA 1.25\% \\
\hline mfVEP latency & $0.77(p<0.001)$ & $0.52(p=0.007)$ \\
\hline Total RNFL thickness & $0.58(p=0.002)$ & $0.46(p<0.02)$ \\
\hline Temporal RNFL thickness & $0.65(p<0.001)$ & $0.54(p=0.005)$
\end{tabular}

Abbreviations: LCVA = low-contrast visual acuity; mfVEP = multifocal visual evoked potentials; RNFL = retinal nerve fiber layer. 
Figure 3 Correlation Between Intereye Asymmetry of LCVA (1.25\% and 2.5\% Contrast) at Baseline With Baseline Latency Asymmetry of mfVEP (A, B) and Baseline Asymmetry of Total (C, D) and Temporal (E, F) RNFL Thickness

A
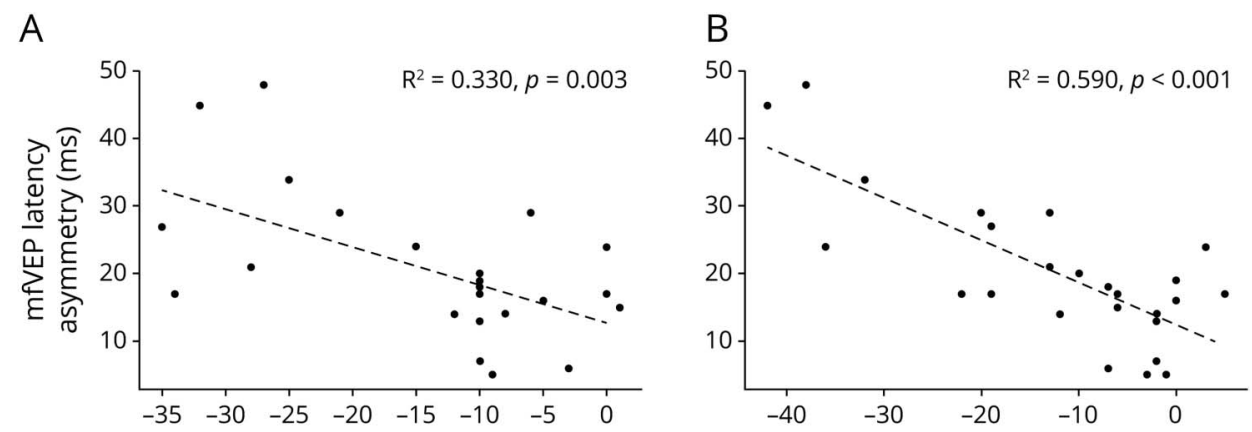

C
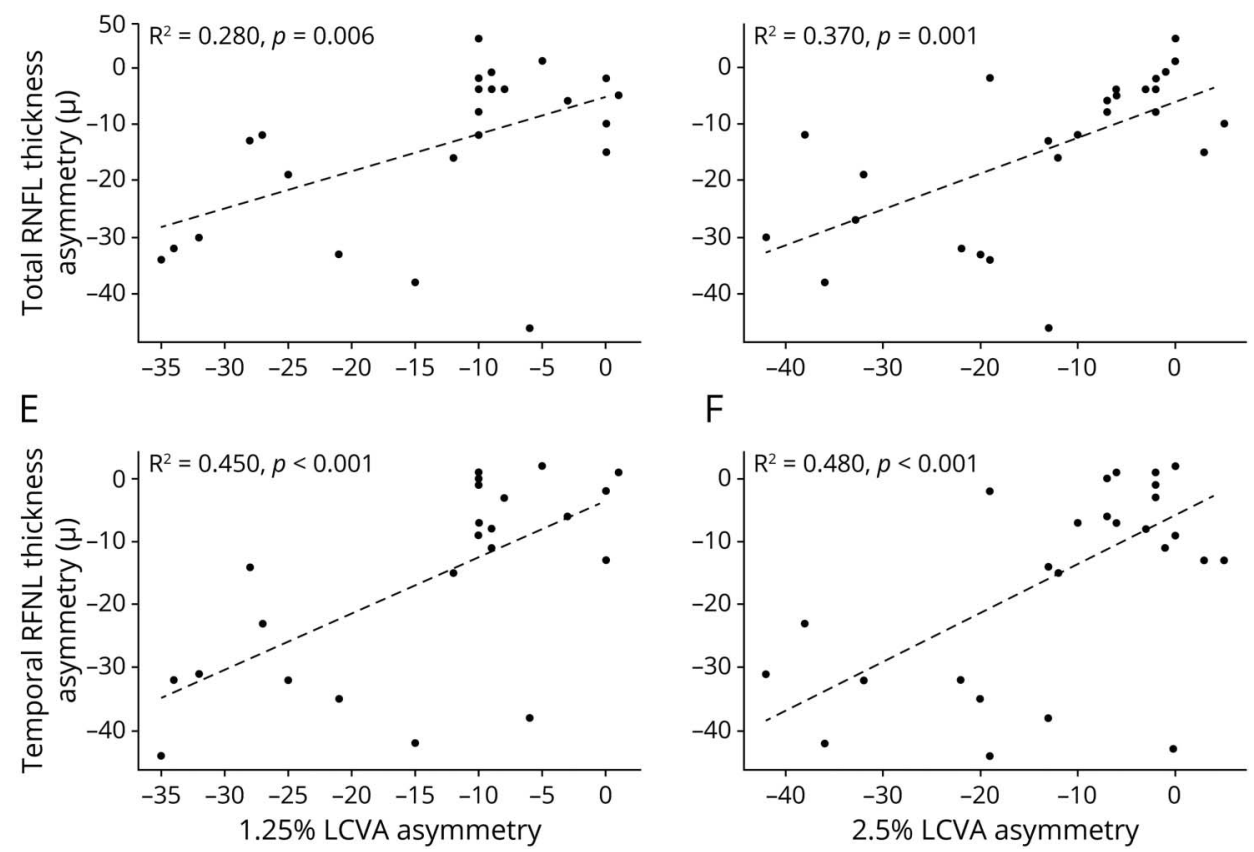

$\mathrm{F}$

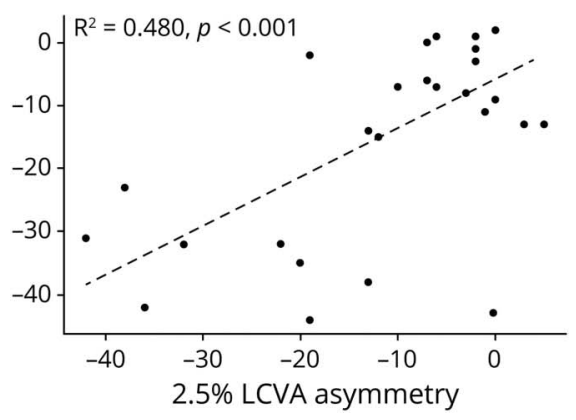

This study benefitted from an even longer (6 years) follow-up period by clearly demonstrating the difference in the rate of RGC axonal attrition between $\mathrm{ON}$ and fellow eyes and a significant correlation between the degree of chronic demyelination and RNFL thinning for both temporal and total RNFL measures. Applying asymmetry analysis and careful patient selection by verifying the presence and degree of chronic demyelination in ON eyes using latency of the mfVEP also provided an additional advantage for this study.

Limited (up to 2 years) observation periods, ${ }^{28,29}$ mixed patient's cohorts, ${ }^{29-31}$ or lack of validation of the degree of chronic demyelination ${ }^{29-31}$ may explain why some of the previously reported studies failed to detect accelerated axonal loss in the eyes of patients with RRMS with a history of ON. The most recent study, ${ }^{32}$ which followed mixed cohort of patients with MS for 5 years, showed a significant relationship between RNFL thinning and previous history of $\mathrm{ON}$ only in the progressive, but not in patients with relapsing-remitting MS. However, contrary to patients with progressive MS, the baseline degree of optic nerve damage caused by acute ON (and, therefore, degree of chronic demyelination) in ON eyes of patients with RRMS was minimal, if any. We believe that the patient selection (using the VEP or OCT criteria ${ }^{33,34}$ ) is extremely important if one wants to study the effects of chronic demyelination because at the time of the enrollment, almost half of the clinically diagnosed patients with $\mathrm{ON}$ in our cohort did not show significant residual chronic demyelination, indicating either potential over-diagnosis or "complete" spontaneous remyelination of optic nerve lesions in the early postacute period. ${ }^{9}$

Our study demonstrated that the process of axonal attrition caused by the chronic loss of myelin, while measurable, is slow and, when combined with the limited sensitivity of modern OCT technology in eyes that have already lost a substantial amount of RNFL, requires a lengthy observation period to be reliably detected. This is contrary to substantial axonal transection occurring during acute $\mathrm{ON},{ }^{35}$ corroborated by significant 
Figure 4 Change mfVEP Latency (A), Total RNFL Thickness (B), and Temporal RNFL Thickness (C) During the Follow-up Period in ON and NON Eyes
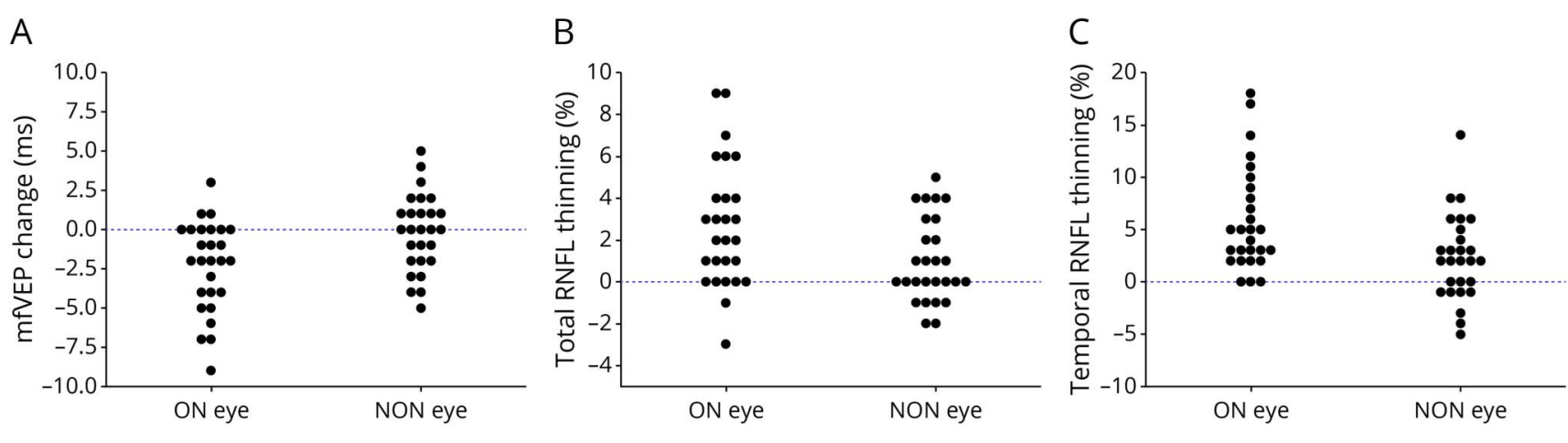

correlation between baseline intereye latency asymmetry (which reflects the length of the acute optic nerve inflammation ${ }^{18}$ ) and baseline intereye RNFL thickness asymmetry.

Although the correlation between mfVEP latency and RGC axonal thinning was statistically significant for both total and temporal RNFL, thinning of the temporal RNFL was more evident and more strongly associated with the degree of chronic demyelination. Better correlations of mfVEP latency with temporal RNFL (both cross-sectionally and longitudinally) are likely to reflect better topographical correspondence between the 2 because the central area of the visual field, which represents most (80\%) of the mfVEP segments, ${ }^{36}$ is subserved by the temporal RNFL. In addition, ON more frequently affects the fibers traveling in the center of the nerve, ${ }^{37,38}$ as manifested by the longest latency delay observed in central mfVEP segments. ${ }^{9}$ This is possibly due to the proximity of those fibers to the central retinal vessels that travel in the anterior nerve head.

LCVA, used in this study as a functional measure of vision, ${ }^{39,40}$ was also significantly diminished in $\mathrm{ON}$ eyes compared with fellow eyes. It demonstrated a significant association with the level of chronic demyelination in optic nerve and baseline asymmetry of RNFL thickness, confirming our previous observation. ${ }^{16}$ The correlation was stronger for $2.5 \%$ compared with $1.25 \%$, which is likely to be due to a higher variability of the $1.25 \%$ LCVA measure. However, although there was a significant reduction of LCVA in both ON and fellow eyes, no correlation was observed between progressive LCVA change in ON eyes and mfVEP latency asymmetry at baseline or the rate of RNFL thinning, implying lower sensitivity of this functional measure in monitoring subtle axonal damage caused by chronic loss of myelin. ${ }^{41}$

There are several limitations in this study. First, there is potentially an alternative explanation for accelerated axonal loss observed in $\mathrm{ON}$ eyes, namely, that slow-burning inflammation at the rim of chronic active MS lesions can potentially cause axonal degeneration and accompanying lesion expansion. ${ }^{42,43}$ Recent studies have demonstrated that this process is frequent even in the relapsing-remitting stage of the disease. ${ }^{44,45}$ This is, however, less likely because there was no electrophysiologic evidence of lesion growth (i.e., no increase

Figure 5 Correlation Between Baseline mfVP Latency Asymmetry and the Rate of Total (A) and Temporal (B) RNFL Thinning
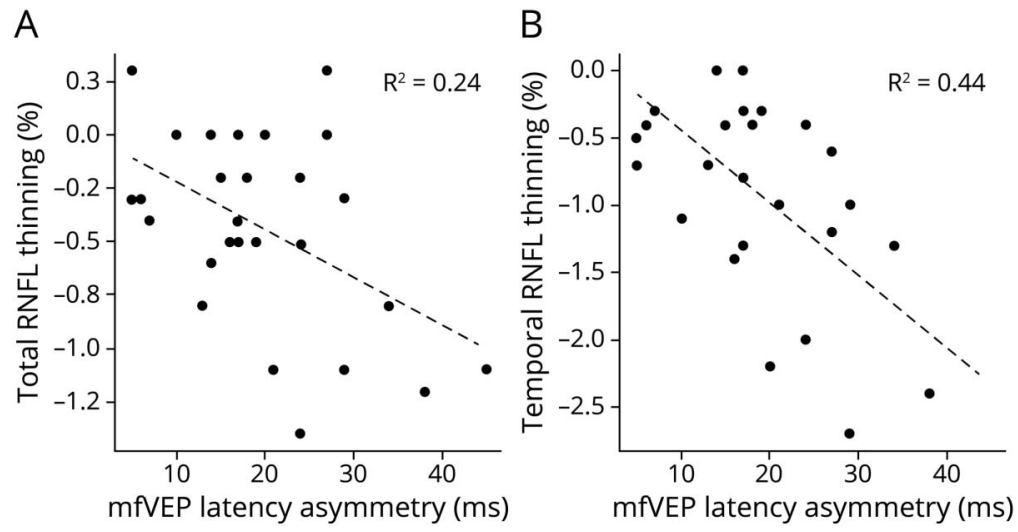
of latency delay in the ON eye or increase of intereye latency asymmetry, which would complement lesion expansion). On the contrary, latency in the ON eye slightly, but significantly, shortened during the follow-up period, suggesting continuous spontaneous remyelination, ${ }^{9}$ cortical plasticity, ${ }^{46}$ beneficial treatment effects, or preferential loss of heavily demyelinated optic nerve axons. The limited effect of slow-burning rim inflammation on axonal loss within lesional tissue may be related to the anatomy of the optic nerve. Thus, geometrically, the optic nerve represents a cylindrical shape with a radius of $1.6-2 \mathrm{~mm}$ and a length of approximatey $45-50 \mathrm{~mm}{ }^{47} \mathrm{An}$ average lesion in the optic nerve, as detected by magnetic resonance imaging, is approximatey $20-25 \mathrm{~mm}$ in length and often occupies the full cross section of the nerve. ${ }^{48}$ As a result, the area of potential expansion is limited to the proximal and distal ends of the lesion along the optic nerve, ${ }^{9}$ contrary to most brain lesions, which are typically fully surrounded by normal white matter. ${ }^{49}$ These anatomical characteristics of optic nerve lesions, therefore, may provide a unique opportunity for investigating the effect of chronic demyelination in isolation.

Our study is limited by relatively small sample size of patients who fitted the specific criteria for inclusion, which may hinder the detection of an association between chronic demyelination and LCVA and limit the potential utility of functional measures of axonal loss.

There is also a possibility that a new episode of ON or the development of new lesions in the optic radiations during the follow-up can potentially result in RNFL loss. However, we do not think that the abovementioned factors would have affected our results. As we have previously shown, new OR lesions can affect the RNFL in both eyes through transsynaptic degeneration, ${ }^{50}$ but this produces similar loss in both eyes and is reflected in a symmetrical delay in the mfVEP. In addition, a new episode of $\mathrm{ON}$ is likely to cause substantial unilateral delay on mfVEP, which was not observed in this study.

Another limitation is related to the fact that patients were on various disease-modifying therapies (DMT) that, in some cases, were changed during the follow-up period. Although this potentially affected our results, there is currently no information related to the effect of DMT on the neuroprotection of chronically demyelinated axons available, and this question remains to be addressed in future studies.

The results of this study may have significant implications for the design of clinical trials of remyelinating agents. For example, even highly sensitive structural measures of axonal loss, such as OCT, required $>5$ years of follow-up to unequivocally establish the effect of chronic demyelination on axonal loss. Therefore, to demonstrate potential neuroprotective effects of treatment-induced remyelination on preventing such a loss, a prohibitively long study duration is likely to be required.

In summary, our study provides clear in vivo evidence that chronic demyelination significantly accelerates axonal loss.
However, because this process is slow and its effect is mild, longterm monitoring is required to firmly establish and confidently measure the neurodegenerative consequences of demyelination.

\section{Study Funding}

The authors disclosed receipt of the following financial support for the research, authorship, and/or publication of this article: Supported by the National Multiple Sclerosis Society (NMSS), Novartis Save Neuron Grant, Sydney Eye Hospital foundation grant, and Sydney Medical School Foundation.

\section{Disclosure}

All authors report no disclosures relevant to the manuscript. Go to Neurology.org/NN for full disclosures.

\section{Publication History}

Received by Neurology: Neuroimmunology \& Neuroinflammation October 10, 2021. Accepted in final form January 24, 2022. Submitted and externally peer reviewed. The handling editor was Friedemann Paul, MD.

\section{Appendix Authors}

\begin{tabular}{|c|c|c|}
\hline Name & Location & Contribution \\
\hline $\begin{array}{l}\text { Alexandr } \\
\text { Klistorner, } \\
\text { PhD }\end{array}$ & $\begin{array}{l}\text { Save Sight Institute, Sydney } \\
\text { Medical School, University of } \\
\text { Sydney, Sydney, New South } \\
\text { Wales, Australia; Faculty of } \\
\text { Medicine and Health } \\
\text { Sciences, Macquarie } \\
\text { University, Sydney, New } \\
\text { South Wales, Australia }\end{array}$ & $\begin{array}{l}\text { Drafting/revision of the } \\
\text { manuscript for content, } \\
\text { including medical writing for } \\
\text { content; major role in the } \\
\text { acquisition of data; study } \\
\text { concept or design; and } \\
\text { analysis or interpretation of } \\
\text { data }\end{array}$ \\
\hline $\begin{array}{l}\text { Samuel } \\
\text { Klistorner, } \\
\text { BSci }\end{array}$ & $\begin{array}{l}\text { Save Sight Institute, Sydney } \\
\text { Medical School, University of } \\
\text { Sydney, Sydney, New South } \\
\text { Wales, Australia; Royal North } \\
\text { Shore Hospital, Sydney, New } \\
\text { South Wales, Australia }\end{array}$ & $\begin{array}{l}\text { Drafting/revision of the } \\
\text { manuscript for content, } \\
\text { including medical writing for } \\
\text { content; study concept or } \\
\text { design; and analysis or } \\
\text { interpretation of data }\end{array}$ \\
\hline $\begin{array}{l}\text { Yuyi You, } \\
\text { PhD }\end{array}$ & $\begin{array}{l}\text { Save Sight Institute, Sydney } \\
\text { Medical School, University of } \\
\text { Sydney, Sydney, New South } \\
\text { Wales, Australia; Faculty of } \\
\text { Medicine and Health } \\
\text { Sciences, Macquarie } \\
\text { University, Sydney, New } \\
\text { South Wales, Australia }\end{array}$ & $\begin{array}{l}\text { Analysis or interpretation of } \\
\text { data }\end{array}$ \\
\hline $\begin{array}{l}\text { Stuart L. } \\
\text { Graham, } \\
\text { PhD }\end{array}$ & $\begin{array}{l}\text { Faculty of Medicine and } \\
\text { Health Sciences, Macquarie } \\
\text { University, Sydney, New } \\
\text { South Wales, Australia }\end{array}$ & $\begin{array}{l}\text { Drafting/revision of the } \\
\text { manuscript for content, } \\
\text { including medical writing for } \\
\text { content, and analysis or } \\
\text { interpretation of data }\end{array}$ \\
\hline $\begin{array}{l}\text { Con } \\
\text { Yiannikas, } \\
\text { PhD }\end{array}$ & $\begin{array}{l}\text { Royal North Shore Hospital, } \\
\text { Sydney, New South Wales, } \\
\text { Australia }\end{array}$ & $\begin{array}{l}\text { Major role in the acquisition } \\
\text { of data }\end{array}$ \\
\hline $\begin{array}{l}\text { John } \\
\text { Parratt, } \\
\text { PhD }\end{array}$ & $\begin{array}{l}\text { Royal North Shore Hospital, } \\
\text { Sydney, New South Wales, } \\
\text { Australia }\end{array}$ & $\begin{array}{l}\text { Major role in the acquisition } \\
\text { of data }\end{array}$ \\
\hline $\begin{array}{l}\text { Michael } \\
\text { Barnett, } \\
\text { PhD }\end{array}$ & $\begin{array}{l}\text { Brain and Mind Centre, } \\
\text { University of Sydney, Sydney, } \\
\text { New South Wales, Australia; } \\
\text { Sydney Neuroimaging } \\
\text { Analysis Centre, } \\
\text { Camperdown, New South } \\
\text { Wales, Australia }\end{array}$ & $\begin{array}{l}\text { Drafting/revision of the } \\
\text { manuscript for content, } \\
\text { including medical writing for } \\
\text { content, and major role in the } \\
\text { acquisition of data }\end{array}$ \\
\hline
\end{tabular}




\section{References}

1. Barkhof F, Jong RD, Sfikas N, Vera AD. The influence of patient demographics, disease characteristics and treatment on brain volume loss in Trial Assessing Injectable Interferon vs FTY720 Oral in Relapsing-remitting multiple sclerosis (TRANSFORMS), a phase 3 study of fingolimod in multiple sclerosis. Mult Scler. 2014;20(13): 1704-1713.

2. Radue EW, Barkhof F, Kappos L, et al. Correlation between brain volume loss and clinical and MRI outcomes in multiple sclerosis. Neurology. 2015;84(8):784-793.

3. Beck ES, Reich DS. Brain atrophy in multiple sclerosis: how deep must we go? Ann Neurol. 2018;83(2):208-209.

4. Damasceno A, Damasceno BP, Cendes F. No evidence of disease activity in multiple sclerosis: implications on cognition and brain atrophy. Mult Scler. 2016;22(1):64-72.

5. Mahad DH, Trapp BD, Lassmann H. Progressive multiple sclerosis 1 Pathological mechanisms in progressive multiple sclerosis. Lancet Neurol. 2015;14(2):183-193.

6. You Yuyi, Barnett MH, Yiannikas C, et al. Chronic demyelination exacerbates neuroaxonal loss in MS patients with unilateral optic neuritis. Neurol Neuroimmunol Neuroinflammation. 2020;7(3):e700.

7. Jenkins $\mathrm{T}$, Ciccarelli $\mathrm{O}$, Toosy A, et al. Dissecting structure-function interactions in acute optic neuritis to investigate neuroplasticity. Hum Brain Mapp. 2010;31(2):276-286.

8. Graham SL, Klistorner AI, Grigg JR, Billson FA. Objective VEP perimetry in glaucoma: asymmetry analysis to identify early deficits. J Glaucoma. 2000;9(1):10-19.

9. Klistorner A, Arvind H, Garrick R, Yiannikas C, Paine M, Graham SL. Remyelination of optic nerve lesions: spatial and temporal factors. Mult Scler. 2010;16(7):786-795.

10. Petzold A, Balcer LJ, Calabresi PA, et al. Retinal layer segmentation in multiple sclerosis: a systematic review and meta-analysis. Lancet Neurol. 2017;16(10):797-812.

11. Polman CH, Reingold SC, Banwell B, et al. Diagnostic criteria for multiple sclerosis: 2010 revisions to the McDonald criteria. Ann Neurol. 2011;69(2):292-302.

12. Behbehani R, Ali A, Al-Omairah H, Rousseff RT. Optimization of spectral domain optical coherence tomography and visual evoked potentials to identify unilateral optic neuritis. Mult Scler Relat Disord. 2020;41:101988.

13. Klistorner A, Triplett JD, Barnett MH, et al. Latency of multifocal visual evoked potential in multiple sclerosis: a visual pathway biomarker for clinical trials of remyelinating therapies. J Clin Neurophysiol. 2020;38(3):186-191.

14. Cruz-Herranz A, alk LJ, Oberwahrenbrock T, et al. The APOSTEL recommendations for reporting quantitative optical coherence tomography studies. Neurology. 2016; 86(24):2303-2309.

15. Tewarie $\mathrm{P}, \mathrm{Balk} \mathrm{L}$, Costello $\mathrm{F}$, et al. The OSCAR-IB consensus criteria for retinal OCT quality assessment. PLoS One. 2012;7(4):e34823-7.

16. Triplett JD, Yiannikas C, Barnett $\mathrm{MH}$, et al. Pathophysiological basis of low contrast visual acuity loss in multiple sclerosis. Ann Clin Transl Neurol. 2018;5(12):1505-1512.

17. Talman LS, Bisker ER, Sackel DJ, et al. Longitudinal study of vision and retinal nerve fiber layer thickness in multiple sclerosis. Ann Neurol. 2010;67(6):749-760.

18. Van Der Walt A, Kolbe $S$, Mitchell $P$, et al. Parallel changes in structural and functional measures of optic nerve myelination after optic neuritis. PLoS One. 2015;10(5): e0121084.

19. Hardmeier M, Leocani L, Fuhr P. A new role for evoked potentials in MS? Repurposing evoked potentials as biomarkers for clinical trials in MS. MSJ. 2017;23(10): 1309-1319.

20. McDonald WI. Pathophysiology of conduction in central nerve fibres. In: Visual Evoked Potentials in Man: New Developments. Clarendon Press; 1977:427-437.

21. Brück W. Inflammatory demyelination is not central to the pathogenesis of multiple sclerosis. J Neurol. 2005;252(suppl 5):v10-v15.

22. Trapp BD, Ransohoff R, Rudick R. Axonal pathology in multiple sclerosis: relationship to neurologic disability. Curr Opin Neurol. 1999;12(3):295-302.

23. Kornek B, Storch MK, Weissert R, et al. Multiple sclerosis and chronic autoimmune encephalomyelitis: a comparative study of axonal injury in active, inactive and remyelinated lesons. Am J Pathol. 2000;157(1):267-276.

24. Dutta R, MsDonough J, Yin X, Peterson J, Chang A. Mitochondrial dysfunction cause of axonal degeneration in multiple sclerosis patients. Ann Neurol. 2006;59(3) 478-489.

25. Correale J, Gaitán MI, Ysrraelit MC, Fiol MP. Progressive multiple sclerosis: from pathogenic mechanisms to treatment multiple sclerosis. Brain. 2017;140(3):527-546. 6. Correale J, Farez MF, Cardona AE. The role of astrocytes in multiple sclerosis progression. Front Neurol. 2015;6:1-12.
27. Klistorner A, Garrick R, Paine M, et al. Relationship between chronic demyelination of the optic nerve and short term axonal loss. J Neurol Neurosurg Psychiatry. 2011;83(3): 311-314.

28. Garcia-Martin E, Pueyo V, Ara JR, et al. Effect of optic neuritis on progressive axonal damage in multiple sclerosis patients. Mult Scler J. 2011;17(7):830-837.

29. Balk LJ, Cruz-Herranz A, Albrecht P, et al. Timing of retinal neuronal and axonal loss in MS: a longitudinal OCT study. J Neurol. 2016;263(7):1323-1331.

30. Abalo-Lojo JM, Treus A, Arias M, Gómez-Ulla F, Gonzalez F. Longitudinal study of retinal nerve fiber layer thickness changes in a multiple sclerosis patients cohort: a long term 5 year follow-up. Mult Scler Relat Disord. 2018;19:124-128.

31. Preiningerova JL, Grishko A, Sobisek L, et al. Do eyes with and without optic neuritis in multiple sclerosis age equally? Neuropsychiatr Dis Treat. 2018;14:2281-2285.

32. Jakimovski D, Zivadinov R, Vaughn CB, Ozel O, Weinstock-Guttman B. Clinical effects associated with five-year retinal nerve fiber layer thinning in multiple sclerosis. J Neurol Sci. 2021;427:117552.

33. Bsteh G, Hegen H, Altmann P, et al. Validation of inter-eye difference thresholds in optical coherence tomography for identification of optic neuritis in multiple sclerosis. Mult Scler Relat Disord. 2020;45:102403.

34. Nolan-Kenney RC, Liu M, Akhand O, et al. Optimal intereye difference thresholds by optical coherence tomography in multiple sclerosis: an international study. Ann Neurol. 2019;85(5):618-629.

35. Kupersmith MJ, Garvin MK, Wang J, Durbin M, Kardon R Retinal ganglion cell layer thinning within one month of presentation for optic neuritis. Mult Scler. 2016;22(5): 641-648.

36. Klistorner A, Arvind H, Nguyen T, et al. Multifocal VEP and OCT in optic neuritis: a topographical study of the structure-function relationship. Doc Ophthalmol. 2009; 118(2):129-137.

37. Gelfand JM, Goodin DS, Boscardin WJ, Nolan R, Cuneo A, Green AJ. Retinal axonal loss begins early in the course of multiple sclerosis and is similar between progressive phenotypes. PLoS One. 2012;7(5):e36847.

38. Rebolleda G, Sánchez-Sánchez C, González-López JJ, Contreras I, Muñoz-Negrete FJ. Papillomacular bundle and inner retinal thicknesses correlate with visual acuity in nonarteritic anterior ischemic optic neuropathy. Invest Ophthalmol Vis Sci. 2015; 56(2):682-692.

39. Baier ML, Cutter GR, Rudick R. Low-contrast letter acuity testing captures visual dysfunction in patients with multiple sclerosis. Neurology. 2015;64(6):992-995.

40. Balcer LJ, Raynowska J, Nolan R, et al. Validity of low-contrast letter acuity as a visual performance outcome measure for multiple sclerosis. Mult Scler. 2017;23(5):734-747.

41. Klistorner A, Barnett MH. Remyelination trials: are we expecting the unexpected? Neurol Neuroimmunol Neuroinflamm. 2021;8(6):e1066.

42. Dal-Bianco A, Grabner G, Kronnerwetter C, et al. Slow expansion of multiple sclerosis iron rim lesions: pathology and $7 \mathrm{~T}$ magnetic resonance imaging. Acta Neuropathol. 2017;133(1):25-42.

43. Elliott C, Wolinsky JS, Hauser SL, et al. Slowly expanding/evolving lesions as a magnetic resonance imaging marker of chronic active multiple sclerosis lesions. Mult Scler. 2019;25(14):1915-1925.

44. Klistorner S, Barnett MH, Yiannikas C, et al. Expansion of chronic lesions is linked to disease progression in relapsing-remitting multiple sclerosis patients. Mult Scler J. 2021;27(10): 1533-1542.

45. Klistorner S, Barnett M, Yiannikas C, et al. Expansion of chronic MS lesions is associated with an increase of radial diffusivity in periplaque white matter. Mult Scler. 2021. Online ahead of print, doi: 10.1177/13524585211033464.

46. Raz N, Chokron S, Ben-Hur T, Levin N. Temporal reorganization to overcome monocular demyelination. Neurology. 2013;81(8):702-709.

47. Frohman EM, Dwyer MG, Frohman T, et al. Relationship of optic nerve and brain conventional and non-conventional MRI measures and RNFL, as assessed by OCT and GDx: a pilot study. J Neurol Sci. 2009;282(1-2):96-105.

48. Trip SA, Schlottmann PG, Jones SJ, et al. Optic nerve atrophy and retinal nerve fibre layer thinning following optic neuritis: evidence that axonal loss is a substrate of MRIdetected atrophy. Neuroimage. 2006;31(1):286-293.

49. Fillipi M. MRI technologies in multiple sclerosis. In: Cook SD, ed. Handbook on multiple sclerosis. Taylor \& Francis; 2005:179-221.

50. Klistorner A, Sriram P, Vootakuru N, et al. Axonal loss of retinal neurons in multiple sclerosis associated with optic radiation lesions. Neurology. 2014;82(24):2165-2172. 


\title{
Neurology \\ Neuroimmunology \& Neuroinflammation
}

\author{
Long-term Effect of Permanent Demyelination on Axonal Survival in Multiple Sclerosis \\ Alexandr Klistorner, Samuel Klistorner, Yuyi You, et al. \\ Neurol Neuroimmunol Neuroinflamm 2022;9; \\ DOI 10.1212/NXI.0000000000001155
}

This information is current as of March 3, 2022

\section{Updated Information \& Services}

References

Subspecialty Collections

Permissions \& Licensing

Reprints including high resolution figures, can be found at:

http://nn.neurology.org/content/9/3/e1155.full.html

This article cites 48 articles, 2 of which you can access for free at: http://nn.neurology.org/content/9/3/e1155.full.html\#\#ref-list-1

This article, along with others on similar topics, appears in the following collection(s):

Evoked Potentials/Visual

http://nn.neurology.org//cgi/collection/evoked_potentials-visual

Multiple sclerosis

http://nn.neurology.org//cgi/collection/multiple_sclerosis

Optic nerve

http://nn.neurology.org//cgi/collection/optic_nerve

Optic neuritis; see Neuro-ophthalmology/Optic Nerve

http://nn.neurology.org//cgi/collection/optic_neuritis

Information about reproducing this article in parts (figures,tables) or in its entirety can be found online at:

http://nn.neurology.org/misc/about.xhtml\#permissions

Information about ordering reprints can be found online:

http://nn.neurology.org/misc/addir.xhtml\#reprintsus

Neurol Neuroimmunol Neuroinflamm is an official journal of the American Academy of Neurology.

Published since April 2014, it is an open-access, online-only, continuous publication journal. Copyright

Copyright $\odot 2022$ The Author(s). Published by Wolters Kluwer Health, Inc. on behalf of the American

Academy of Neurology.. All rights reserved. Online ISSN: 2332-7812.

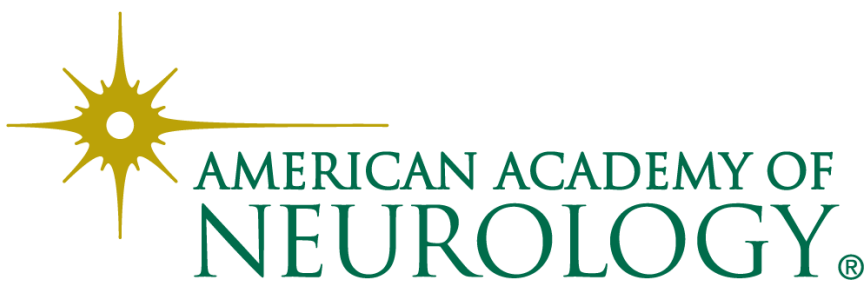

